\title{
The research of land resources e-government system of Henan province based on GIS
}

\author{
Cheng Xiaoxu ${ }^{1, a}$ \\ ${ }^{1}$ Administrative Management, Tianjin university of commerce, Tianjin, 300134, China \\ achengxiaoxu_tjs@163.com
}

Keywords: E-government system, GIS, land resources, information system

\begin{abstract}
Pointing at the shortage of the informatization of the existing land resources and the need of the coordinated operation of the whole process of all the land resources business of three levels of province, city, county. Based on the construction of multistage and integration administrative management platform of land resources, taking the build of multistage and integration administrative management platform that applying to all land resources administration systems of the system of the management of provincial integrated affair, the examinational and approval system of provincial construction land, the examinational and approval system of provincial mining rights, the provincial integrated supervision system as goal, realizing the three-level coordination management of province, city, county. Studying the functional requirements of the construction of e-government platform deeply, based on the design of the GIS construction to build the unified technology platform of the administration system of land resources; Studying the functional requirements of the system of the management of provincial integrated affair, the examinational and approval system of provincial construction land, the examinational and approval system of provincial mining rights, the provincial integrated supervision system and and other related subsystem deeply, designing a system that meet the related function, to achieve the online operation of the management of all business of land resources of three levels of the province, city and county and interconnection.
\end{abstract}

\section{Introduction}

E-government platform is the core of the application of the e-government system of land resources, is the foundation of the normal operation and customization of system, which plays a role of linking, supporting the application of service system for the preceding, playing the unified scheduling effect on resources and data interaction of the following. It is the general kernel of scheduling action of system. An excellent platform of e-government should have characteristics of good extensibility, integration, rapid business customization, and good stability, fast response and so on. In the field of land resources application, it also needs to adapt to the requirements of multilevel data collection, therefore, we must have full consideration on the abilities of platform performance, transverse and longitudinal integration and the business rapid customization, forming a unified land resources e-government platform of three levels of province, city and county. 


\section{The overall technology roadmap}

According to the need analytical, combining the analysis of the basic construction condition of the information of the land resources system, the basic requirements of construction technology route of the information of land resources administration system.

\section{The establishment of the multilevel administration platform of land resources with SOA architecture}

Researching and developing the provincial unified and multilevel integration land resources e-government administration platform, and building business being on the basis of platform, providing public service components through the platform, realizing the second development of features of integration of application systems, accordant organization, Single sign-on, unified rights management, business process customization, business modeling, business form customization, report customization, rapidly building the land resources service system, realizing data exchange and share of each operation system; through the componentization of the business functions service of business system, to provide good component library for future development of other business system. Using the service oriented architecture and multilevel integrated e-government management platform of land resource, it will contribute to achieve the overall framework of multilevel integrated e-government management system of land resource and provide foundation for the construction of the three models (centralized model, distributed isomorphic model, distributed heterogeneous model) of the business system of the provincial land resources department.

\section{System development based on model driven}

The complexity of the information systems are often not in terms of technology, but in the business itself. If the complexity in business fields was not handled well in the design, no matter how good the infrastructure technology is it also be of no avail. Land resources information system is a large scale information engineering that the span of transverse business and longitudinal administrative levels are very big, the key business data are massive spatial data, it is difficult to directly analyze and design it, it needs the help of business modeling to analyze and design the system, establishing the function model, information model, data model, control model and decision model of business, through the business model to understand, analysis, develop, evaluate and improve the design scheme of information system, it helps to clarify the mutual relationship between the various business, realizing the mutual integration of business data, eliminating data redundancy and cross functional, breaking the isolated island of information, enhancing the data sharing, optimizing business processes, comprehensively breakthrough the present mode of administrative functional segmentation and traditional business functions software, to achieve the integration of business. At the same time, sort out the relationship of the mutual alignment and balance among the business data, and also provide the foundation condition for the mutual supervision of data service and the find of false data. It is also conducive to the overall planning, focus, the implement step by step, on the basis of business model, according to the integration of construction idea, to carry out the work of informatization in a planned and focused way. 


\section{The operation of the system and the response speed of system}

The design and development of the system is based on the thought of Web2.0 that the industry respecting at present, providing a business system that easy operation, easy to use, richly show content for users. The system should provide a variety of means of operation graphically, giving full play to the characteristics of GIS that face the user in graphics, the manifestation mode of information is more intuitive and more efficient. At the same time, the interface of all kinds of screen format, the format of report, the format of menu adopts the rich client (RIA), providing a good experience of user. For the response of the system can achieve the degree of the user can receive; system runs fast and can achieve the requirements of land business processing, map browsing, network query and other day jobs. The system should have a unified style for various response.

\section{The combination of centralized and distributed data center mode}

The data center is to meet all types of storage of land resources data, management needs and providing the basic hardware and software environment for land resources e-government platform, the operational environment for all kinds of business information management application system. Based on the characteristics of data management and business management of land resources, according to the combination of centralized and distributed mode to construct the data center of land resources of the two levels of province and city. On the one hand, the land resources management departments of all levels should centralize and deploy the e-government platform and business management system of the same level in the data center of the level; on the other hand, forming multilevel distributed data center to realize the linkage of the operation of provincial business management system of all levels and the updating of database, to provide services of the administrative examination and approval and decision support for land management departments at all levels.

\section{The integration of OA, MIS and GIS}

Business data of land and resources department contains too many graphics and attribute data, if stored and processed separately, it will not only make the efficiency low, but also block the further integration and development of the business. In order to achieve "grant and control the land according to the graph"to establish a unified data model of graphic data and business data (object oriented "graphic regardless of metadata model"); On the construction of the frame of function system, require to integrate OA, MIS, GIS for application, make the business approval workflow, MIS management and analysis function of GIS graphics management unify as one. Specifically performing in three aspects: data integration, process integration, application integration.

\section{Apply the composite structure of main and auxiliary of $B / S$ and $C / S$}

The system provides a centralized, distributed, hybrid and other deployment, through data exchange system to realize the multistage data exchange between the superior and subordinate system nodes. In the construction of the system mainly set up two level nodes: provincial node and provincial and municipal node. Accordingly, various subsystems that need multilevel linkage adopt distributed deployment in the node, through the data exchange system to realize the multistage data exchange between the upper and lower system; subsystems that do not need the multilevel linkage adopt centralized deployment in provincial node, city, county access through the 
private network of land; hybrid deployment is that unified the distributed and the centralized, so it can realize the application of the distributed and also can realize the application of the centralized, through the integration of platform of e-government portal, to realize the system with seamless connection. The system provides two types of client operation platform, one is the client with $\mathrm{B} / \mathrm{S}$ structure, providing a unified application environment for leaders and professional personnel of all levels; the other is the client with $\mathrm{C} / \mathrm{S}$ structure, mainly facing to data maintenance management and part of the business personnel that have more requirements in the map processing. The system take $\mathrm{B} / \mathrm{S}$ as main, $\mathrm{C} / \mathrm{S}$ as a supplement, the two modes are complementary, to achieve specific requirements.

\section{The secondary development interface of various forms}

The system should provide various forms of secondary development interface, in order to ensure the scalability of the system. The secondary development interface that the system provide include: business and data expansion tool, the interface of user custom stored procedure, script editing interface, plug-in interface, the platform interface of the secondary development of client, secondary development interface component (various middle ware engine). By the transfer of interface and the extending of application tool, can ensure the connection with other systems and meet the adaptive and self expanding demand of different levels.

\section{data exchange system}

Take the business network of land resources as the basis, take the data center of province, city, county as node, based on the application service bus of multilevel integration of e-government management platform, develop the provincial land and resources data exchange system, to provide a soft channel of safe, reliable, efficient, standardized data transmission for the data exchange(spatial data / non spatial data ), synchronization, sharing of the data of all levels of province, city, county, providing the logic data exchange channel for the switch between internal and external network data of single level. Data exchanging system should be based on the provincial local conditions and by using the flexible deployment mode of the centralized distribution mixture, it should be able to integrate homogeneous and heterogeneous business systems that relate to provincial levels(independent of operating system, database platform, GIS platform, development platform and Technology Architecture), to achieve the integration of the main business and o main process of provincial land resources management, the safe and efficient coordinated office and information sharing. Data exchange system mainly includes: the management platform: deployed in province and qualified city, county bureau, to configure and maintain the exchange route, the role of organization staff, the exchange of resources, the exchange power, exchange standard and so on of the land resources of scope, to track, monitor and make statistical analysis of exchange process, status etc.of the land resources of scope. The prepositive adapter: deployed in the prepositive machine of data exchange of three levels of province, city, county, bearing the data capture, service encapsulation and message listener, message processing and other function of business system. Exchange database: deployed in province and qualified city, county bureau, is the data storage media for all types of data that via a data exchange platform in the process of storing and exchanging data. 


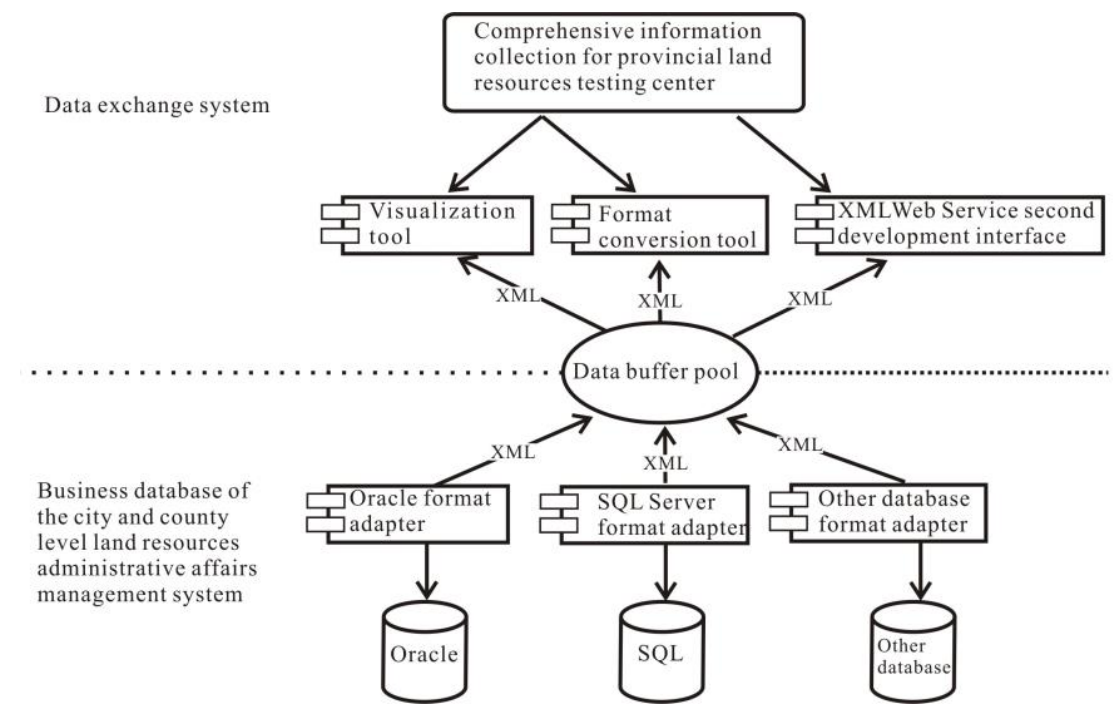

Figure. 1 The data exchange and integration model of land resources of Henan province

\section{The examination and approval system of provincial construction land}

Based on the multilevel integration e-government management platform of land resources, following the technical specification of platform application, developing the examination and approval system of provincial construction land, and making smooth migration for the construction land that have been running of provincial level, being compatible with the electronic offer declaration system and construction of land remote declaring system of the existing construction land.

To achieve the whole information management of the approval of agricultural land conversion and land acquisition business of the provincial people's government, the management review of the separately located project that the State Council approved and agricultural land conversion and the implementation plans of land acquisition and other business, including the functions of connector review, planning management function, the land use planning review, the review of the right of territorial area, the review of supplementary of cultivated land, the review of providing land, agricultural land conversion and land acquisition review, placement examination, financial budget review fees, quasi documents and all kinds of query and statistics and so on. The system must be compatible with the data of the examination and approval of construction land in every stage of land use of new,old and transition class. At the same time, realizing the data connection of construction land examination and approval system of the Ministry of land resources. Based on GIS development platform of E-government in multistage integration management platform, realizing the function of graphical review of approval of construction land, including spatial topology check function, project space check function, the check of illegal land occupation, the function of the graphics review of the right of territorial area, the function of graphic examination of land use planning, the function of graphic examination of the supplementary of cultivated land, the function of the reduction of the occupancy of basic farmland and so on. At the same time, connect with "a map" database and comprehensive supervision system of provincial office, to achieve the project space coordinates and business information review storage and comprehensive supervision function, the system function structure is in Figure 2 


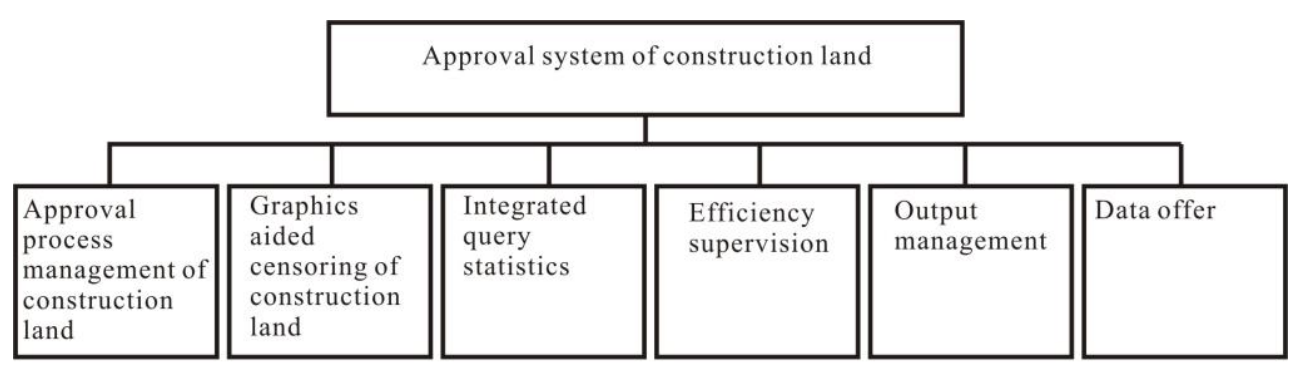

Figure. 2 Approval system of construction land

\section{Summary}

In order to meet the increasing demand, land resources e-government must be constantly upgrade in the process of use, to meet the requirements government and the masses, which focuses on the upgrading of three aspects: First of all, we need to improve the integration of land resource information, our system only realized the unified integration of three levels of province, city, county, but with the development of the times, in the near future, we may have a unified management of land resources information throughout the country, so it requires us to integrate the land resources information in higher level, to meet the interconnection of the central to local. Secondly, we need to upgrade server performance that provide service of land resources e-government system, with the growing quantity of information and the access number increasing instantly, in order to realize the smooth performance of business operation, we need to constantly upgrade the server to adapt to various possible changes. Finally, we need to improve the safety performance of land resources e-government system, with the continuous increase of land resources information stored in the system, if the system exist flaw, especially the vulnerabilities in network, will cause the leakage of a large number of the land resources information even the information of the whole country, this will be a very dangerous thing, we must pay our enough attention to it.

\section{Reference}

[1] Connor J, Ward J, Thomson D, Clifton C. Design and implementation of a land holder agreement for recharge credit trade in the upper Bet Bet Creek catchment, Victoria. CSIRO

Land and Water Report S/04/1845, Canberra, 2004.

[2] Fang, Z. E-Government in Digital Era: Concept, Practice, and Development. International Journal of The Computer, The Internet and Management,2002,10(2):1-22.

[3] Goodchild, M.E.. Geographic information science and systems for environmental management. Annual Review of Environment and Resources, 2003, 28:493-519. 